\title{
Free Vibration of Laminated Composite Curved BeamsUsing Mixed Finite Element Formulation
}

\author{
Fethi Kadioglu* and Cihan Íyidogan \\ Faculty of Civil Engineering, Istanbul Technical University, ITU, 34469 Maslak, Istanbul-Turkey. \\ Phone: +90212285 3706. Fax: +902122856587.
}

\begin{abstract}
Free vibration analysis of a cross-ply laminated composite curved beam was investigated by the Gâteaux differential method in this paper. Natural frequencies of the curved beam are computed using the mixed finite element formulation on the basis of the Timoshenko beam theory including the shear deformation. The finite element model consists of a total of six degrees of freedom, two displacements $\left(u_{n}, u_{t}\right)$, a rotation $\left(\Omega_{b}\right)$, two shear forces $\left(T_{n}, T_{t}\right)$ and a bending moment $\left(M_{h}\right)$. The results of natural frequencies of laminated composite curved beams obtained through the present formulation are in good agreement with the data available in the literature. The effect of different arrangements (symmetric and non-symmetric) of layers in the laminated composite curved beams are compared for various boundary conditions and discussed.
\end{abstract}

Keywords: composite, cross-ply, laminated, curved beam, in plane, free vibration, frequency

\section{INTRODUCTION}

Laminated composites can be arranged in layers with different properties in order to obtain good mechanical properties. Composite materials are being used in many fields including, civil engineering, aerospace, automobile, nuclear, marine chemical industries, and biomedical engineering. The reasons are composites offers high strength-toweight ratios, the ability to bear different strengths in different directions, superior fatigue characteristics, and the ability to be tailored to satisfy the strength and stiffness requirements in practical design applications. The reader is referred to Jones /1/ and Reddy /2/ for an introductory text on composites and comprehensive text on mechanics of laminated composites respectively. In industrial applications, plates and shells are largely composed for structural systems, many times requiring beam reinforcement. Analytical and numerical methods can be employed for the analysis of structural systems composed of laminated composite components. In recent years, some papers about free vibration of laminated composite straight beams have been published in the literature /3-11\% It is important to consider an overview of the free-vibration characteristics which includes the natural frequencies of composite structures, in the dynamic analyses. The effect of the transverse shear deformation has to be considered in the dynamic analysis, since the ratio of extensional modulus to transverse shear modulus is high.

There are only a few papers /12-13/ published in recent years considering in-plane static analysis of laminated curved beams made of composite materials, and very limited studies dealing with the dynamic analysis of laminated curved composite beams /14-18/. . Yildirim /17/ studied non-dimensional in-plane free vibrational characteristics of circular arches considering all the parameters affecting natural frequencies. Qatu $/ 18 /$ presented a set of in-plane

* Corresponding author. E-mail:fkadioglu@itu.edu.tr 
equations and their solutions for laminated shallow arches having simply supported boundary conditions by using polynomial trial functions. The effect of axial and shear deformations and the rotary inertia were neglected in /18/. Qatu and Elsharkawy /19/ studied the in-plane free vibration of anti-symmetric laminated arches with deep curvature and arbitrary boundaries. In-plane free vibration analysis of moderately thick laminated circular beams was studied by Qatu $120 \%$.

A review of the vibration analyses of laminated composite beams was presented by Kapania and Raciti $/ 21 /$. Miller and Adams $/ 22 /$ studied the vibration characteristics of symmetrically orthotropic clamped-free beams using classical lamination theory without including the effect of shear deformation. Chen and Yang /23/ and Chandrashekhara et al /24/ studied free vibration analysis of symmetrically laminated beams, which were based on the first order shear deformation theory. The free-vibration characteristic of laminated composite beams using a higher-order plate theory was studied by Chandrashekhara and Bangera /25/. Khdeir and Reddy /26/ obtained the analytical solutions in conjunction with the state space approach for the free-vibration behavior of cross-ply beams.

In the present paper, the free-vibration characteristics of curved laminated composite beams vibrating in their planes are studied. The Gâteaux differential approach is employed to construct the functional, using variational methods. The solutions are determined by minimizing the functional which allows a finite element computation technique. The finite element developed for curved laminated beams has two nodes with six degrees of freedom per node. The Gâteaux Differential Method (GDM) has been successfully applied in obtaining functionals for the static analysis of elastic and viscoelastic beams by Akoz and Kadioglu /27-29/. The GDM has also been applied to the mixed finite element formulation in dynamic analysis of orthotropic plates resting on a Pasternak foundation by Omurtag and Kadioglu $/ 30 \%$. This study expands the GDM formulation for curved beams to laminated composite materials. The literature review indicates that the natural frequencies of laminated composite curved beams have not yet been investigated using the GDM formulation.

\section{THE FIELD EQUATIONS}

The following assumptions are used in the formulation. Rotary and warping inertia effects are neglected. The beam is made of linear elastic, homogeneous and orthotropic materials which have a uniform cross sectional area. The deformations are small and there is a linear relationship between forces and deformations. The Frenet unit vectors, associated with the beam axis (Fig.l), are used for laminated circular beams. $t$ is tangent vector. The normal (n) and binormal (b) axes are the principal axes. The field equations of initially twisted composite space rods are given by Yildirim 131 . Referring to this study, the following equations are obtained for in-plane free vibrations of both symmetric and non-symmetric cross-ply laminated circular beams $(t=1, n=2, b=3)$ as shown in Figure 1 and as given Yildirim /16/:

$$
\begin{aligned}
& \frac{d u_{1}}{d \theta}=u_{n}+R \Lambda_{11}^{\prime} T_{1} \\
& \frac{d u_{n}}{d \theta}=-u_{1}+R \Omega_{b}+R k^{\prime} A_{22}^{\prime} T_{n} \\
& \frac{d \Omega_{b}}{d \theta}=R D_{33}^{\prime} M_{b} \\
& \frac{d T_{b}}{d \theta}=T_{n}-R \bar{A} \omega^{2} u_{1} \\
& \frac{d T_{n}}{d \theta}=-T_{1}-R \bar{A}()^{2} u_{u} \\
& \frac{d M_{b}}{d \theta}=-R T_{n}
\end{aligned}
$$



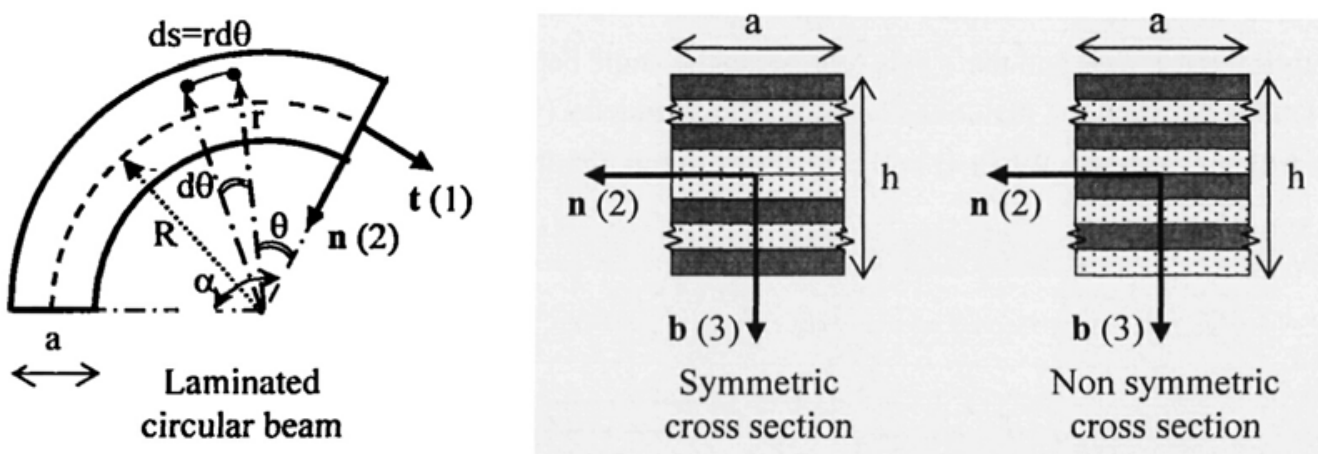

Fig. 1: $N$-layer laminated composite circular beam and system of coordinates.

The field equations contain six variables which are the tangential and transverse displacements, the normal rotation, the tangential and transverse stress resultants, and the moment resultant which are respectively denoted by $u_{n,} u_{t}, \Omega_{b}, T_{n}$ $T_{h}$ and $M_{b} . k^{\prime}$ is the shear coefficient factor, $\omega(\mathrm{rad} / \mathrm{s})$ is the circular frequency and $d s(=R d \theta)$ is the infinitesimal length of the beam. Others terms in the field equations are as follows,

$\overline{\mathrm{A}}=\sum_{k=1}^{\mathrm{N}} \rho^{(k)} \mathrm{A}^{(k)}$

$k$ represents the number of plies, and the density of the material which denotes $\rho$, and A is the undeformed cross sectional area.

$\mathrm{A}_{11}^{\prime}=1 / \sum_{k=1}^{\mathrm{N}} \overline{\mathrm{Q}}_{11}^{(k)} \mathrm{A}^{(k)} \quad \mathrm{A}_{22}^{\prime}=1 / \sum_{k=1}^{\mathrm{N}} \overline{\mathrm{Q}}_{22}^{(k)} \mathrm{A}^{(k)} \quad \mathrm{D}_{33}^{\prime}=1 / \sum_{k=1}^{\mathrm{N}} \overline{\mathrm{Q}}_{11}^{(k)} \mathrm{I}_{\mathrm{b}}^{(k)}$

The cross sectional rigidities in the field equations are given in the above. $\bar{Q}$, which is the element of the transformed reduced stiffness matrix for a lamina, is obtained as follows:

$\overline{\mathrm{Q}}_{11}=\left(\mathrm{C}_{11}^{\prime} \mathrm{S}_{11}^{\prime}+\mathrm{C}_{12}^{\prime} \mathrm{S}_{12}^{\prime}+\mathrm{C}_{13}^{\prime} \mathrm{S}_{13}^{\prime}\right) / \mathrm{S}_{11}^{\prime} \quad \overline{\mathrm{Q}}_{22}=\mathrm{C}_{66}^{\prime} \quad \overline{\mathrm{Q}}_{33}=\mathrm{C}_{55}^{\prime}$

$\mathrm{C}_{\mathrm{ij}}^{\prime}$ is the elements of the transformed stiffness and $\mathrm{S}_{\mathrm{ij}}^{\prime}$ denote by compliance matrices for transversly isotropic material .These are given by Yildirim /31/ as follows:

$$
\begin{aligned}
& C_{11}^{\prime}=m^{4} C_{11}+2\left(m^{2}-m^{4}\right) C_{12}+C_{22}\left(1-2 m^{2}+m^{4}\right)+4\left(m^{2}-m^{4}\right) C_{66} \\
& C_{12}^{\prime}=\left(m^{2}-m^{4}\right) C_{11}+\left(m^{2}-m^{4}\right) C_{22}+C_{12}\left(1-2 m^{2}+2 m^{4}\right)-4\left(m^{2}-m^{4}\right) C_{66} \\
& C_{13}^{\prime}=m^{2} C_{13}+\left(1-m^{2}\right) C_{23} \\
& C_{22}^{\prime}=\left(1-2 m^{2}+2 m^{4}\right) C_{11}+2\left(m^{2}-m^{4}\right) C_{12}+m^{4} C_{22}+4\left(m^{2}-m^{4}\right) C_{66} \\
& C_{23}^{\prime}=m^{2} C_{23}+\left(1-m^{2}\right) C_{13} \\
& C_{55}^{\prime}=\left(1-m^{2}\right) C_{44}+m^{2} C_{55} \\
& C_{66}^{\prime}=\left(m^{2}-m^{4}\right) C_{11}-2\left(m^{2}-m^{4}\right) C_{12}+C_{66}\left(1-4 m^{2}+4 m^{4}\right)+\left(m^{2}-m^{4}\right) C_{22} \\
& S_{11}^{\prime}=m^{4} S_{11}+2\left(m^{2}-m^{4}\right) S_{12}+S_{22}\left(1-2 m^{2}+2 m^{4}\right)+\left(m^{2}-m^{4}\right) S_{66} \\
& S_{12}^{\prime}=\left(m^{2}-m^{4}\right) S_{11}+\left(m^{2}-m^{4}\right) S_{22}+S_{12}\left(1-2 m^{2}+2 m^{4}\right)-\left(m^{2}-m^{4}\right) S_{66} \\
& S_{13}^{\prime}=m^{2} S_{13}+\left(1-m^{2}\right) S_{23}
\end{aligned}
$$


where $m=\cos \beta$ and also $\beta$ is the angle between the beam axis and the material symmetry axis as shown in Figure 2 . The angle $\beta$ between the $1^{\prime}$ axis and the 1 axis represents the angle between the fiber direction and the beam axis. Figure 2 shows the relations between the material axes of elastic symmetry $\left(1^{\prime}, 2^{\prime}, 3^{\circ}\right.$ coordinate system) and the bcam principal axes $\left(\mathbf{t}, \mathbf{n}, \mathbf{b}\right.$ coordinate system). When $\beta=0$, the fibers are in circumferential direction, when $\beta=90^{\circ}$, the fibers are in radial direction.

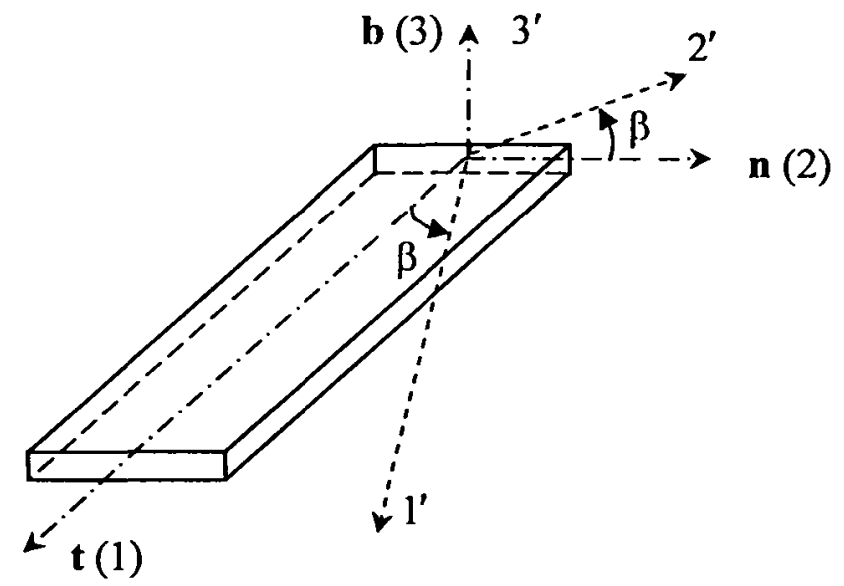

Fig. 2: Relationship between principal material axes $\left(1^{\prime}, 2^{\prime}, 3^{\prime}\right)$ and beam axes $(\mathbf{t}, \mathbf{n}, \mathbf{b})$.

\section{THE GÂTEAUX DIFFERENTIAL AND FUNCTIONAL}

The GDM technique can easily be applied to any field equations for which a stationary functional is not known beforehand. In addition, the operator form of the equations is tested regardless of the potential. In GDM, all the formulation is carried out this operator form and boundary condition terms (dynamic and geometric) are obtained by variational techniques.

In general, field equations can be written in operator form as

$\boldsymbol{L y}-\boldsymbol{f}=\mathbf{0}$

$Q=L \mathbf{y}-\boldsymbol{f}$

Using the Gâteaux differential /32/,

$\mathrm{dQ}(\mathbf{y}, \overline{\mathbf{y}})=\left.\frac{\partial Q(\mathbf{y}+\eta \overline{\mathbf{y}})}{\partial \eta}\right|_{\eta=0}$

$\mathbf{Q}$ is a potential if the equality

$\left\langle\mathrm{d} Q(\mathbf{y}, \overline{\mathbf{y}}), \mathbf{y}^{*}\right\rangle=\left\langle\mathrm{d} Q\left(\mathbf{y}, \mathbf{y}^{*}\right), \overline{\mathbf{y}}\right\rangle$

is satisfied $/ 32 /$ where $\mathrm{d} Q(\mathbf{y}, \overline{\mathbf{y}})$ is the Gâteaux derivative of $\mathbf{Q}$ and the inner product of two vectors. Therefore the functional corresponding to the field equations is obtained as $/ 32 /$

$I(y)=\int_{0}^{1}\langle Q(\tau y, y), y\rangle d \tau$ 
where $\tau$ is a scalar quantity. Details of the variational procedures can be found in Akoz and Kadioglu /27/. Finally from Eq. (9), the functional $I(y)$ of the laminated composite circular beam is obtained.

$$
\begin{aligned}
& I(y)=-\frac{\omega^{2} \bar{A} R}{2}\left[u_{n}, u_{n}\right]-\frac{\omega^{2} \bar{A} R}{2}\left[u_{t}, u_{t}\right]-R\left[T_{n}, \Omega_{b}\right]+\left[u_{t}, T_{n}\right]-\left[u_{n}, T_{t}\right]-\left[T_{n}^{\prime}, u_{n}\right] \\
& -\left[T_{t}^{\prime}, u_{t}\right]-\left[M_{b}^{\prime}, \Omega_{b}\right]-\frac{R D_{11}^{\prime}}{2}\left[M_{b}, M_{b}\right]-\frac{R D_{22}^{\prime}}{2}\left[T_{n}, T_{n}\right]-\frac{R k^{\prime} A_{33}^{\prime}}{2}\left[T_{1}, T_{t}\right]+\left[\hat{u}_{n}, T_{n}\right]_{\varepsilon} \\
& +\left[\tilde{u}_{t}, T_{t}\right]_{\varepsilon}+\left[\hat{\Omega}_{b}, M_{b}\right]_{k}+\left[\left(T_{n}-\hat{T}_{n}\right), u_{n}\right]_{b}+\left[\left(T_{t}-\hat{T}_{t}\right), u_{t}\right]_{b}+\left[\left(M_{b}-\hat{M}_{b}\right), \Omega_{b}\right]_{b}
\end{aligned}
$$

where $[$,$] is the inner product which is defined as$

$$
[f, g]=\int f g R d \theta
$$

The brackets with subscript $\sigma$ are valid on the boundary. The dynamic boundary conditions are set, and similarly, the brackets with subscript $\varepsilon$ are valid on the boundary where the geometric boundary conditions are specified. Terms with " " " are valid if the boundary conditions are known, otherwise they vanish.

\section{THE MIXED FINITE ELEMENT FORMULATION AND DYNAMIC ANALYSIS}

Firstly the interpolation function must be chosen to derive the finite element formulations. The compatibility and completeness requirements must be satisfied by the linear interpolation $/ 33 /$.

$\Psi_{1}=\frac{R\left(\theta_{1}-\theta\right)}{L_{e}} \quad \Psi_{J}=\frac{R\left(\theta-\theta_{1}\right)}{L_{e}}$

where the adopted notation is illustrated in Figure 3 and $L_{e}$ is the length of an element as $R\left(\theta_{1}-\theta_{1}\right)$. All unknown internal quantities are expressed by using interpolation functions as follows:

$$
\begin{aligned}
u_{n} & =u_{n t} \Psi_{i}+u_{n j} \Psi_{j} \\
u_{t} & =u_{t} \Psi_{1}+u_{t j} \Psi_{j} \\
\Omega_{b} & =\Omega_{b i} \Psi_{i}+\Omega_{b j} \Psi_{j} \\
M_{b} & =M_{b i} \Psi_{i}+M_{b j} \Psi_{j} \\
T_{n} & =T_{n t} \Psi_{1}+T_{n j} \Psi_{j} \\
T_{t} & =T_{t} \Psi_{t}+T_{t j} \Psi_{j}
\end{aligned}
$$

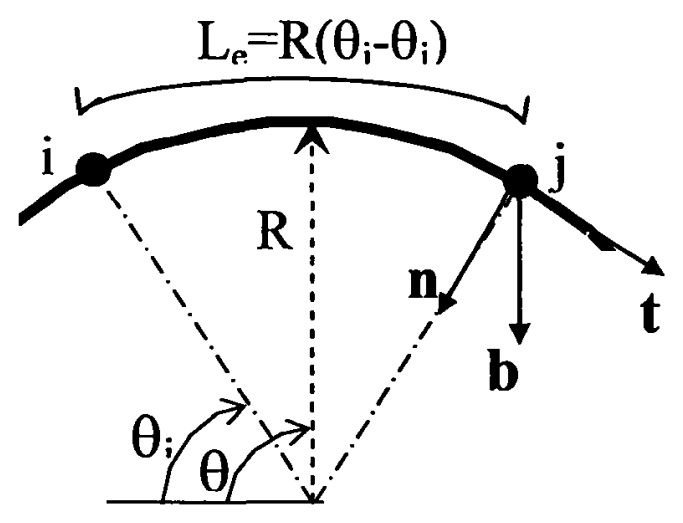

Fig. 3: The two node one-dimensional element for circular beam. 
All equations of unknown quantities in terms of interpolation functions which are given in Eq. (13) are inserted into Eq. (10). Extremization of this functional with respect to twelve nodal variables is completed in order to obtain 12 element equations. Mixed element is based upon a consistent mass matrix formulation in dynamic analysis.

The problem of the natural frequencies of free vibrating structural system reduces to the solution of the standard eigenvalue problem, for dynamic analysis.

$$
[\mathbf{K}]-\mathbf{\omega}^{2}[\mathbf{M}]=\mathbf{0}
$$

where $[\mathbf{K}]$ is the system matrix, $[\mathbf{M}]$ is mass matrix and $\omega$ natural angular frequency of the system, respectively. Thus the problem yields to the following eigenvalue system of equations.

$\left(\left[\begin{array}{ll}{\left[K_{11}\right]} & {\left[K_{12}\right]} \\ {\left[K_{21}\right]} & {\left[K_{22}\right.}\end{array}\right]-\omega^{2}\left[\begin{array}{ll}{[0]} & {[0]} \\ {[0]} & {[11}\end{array}\right]\right)\left\{\begin{array}{l}{[\mathrm{F}]} \\ {[w]}\end{array}\right\}=\left\{\begin{array}{l}{[0]} \\ {[0]}\end{array}\right\}$

where $\{\mathbf{F}\}=\left\{\begin{array}{lll}\mathrm{T}_{\mathrm{n}} & \mathrm{T}_{\mathrm{t}} & \mathrm{M}_{\mathrm{b}}\end{array}\right\}^{\mathrm{T}}$ denote the stress resultants and $\{\mathbf{w}\}$ is defines the transverse displacement vectors. Elimination of $\{\mathbf{F}\}$ from Eq. (15) yields

$$
\left(\left[\mathbf{K}^{*}\right]-\omega^{2}[\mathbf{M}]\{\mathbf{w}\}=\{\mathbf{0}\}\right.
$$

where

$$
\left[K^{*}\right]=\left[K_{22}\right]-\left[K_{21}\right]\left[K_{11}\right]^{-1}\left[K_{12}\right]
$$

and $\left[K^{*}\right]$ is defined as the condensed system matrix of the problem.

\section{NUMERICAL EXAMPLES}

Based on the above formulation several numerical examples are studied. The numerical results to be presented are for cross-ply laminated circular composite beams having a rectangular cross-section. The shear correction factor is taken to be 6/5. All of the results consider the axial and shear deformation effects. A general purpose, Fortran computer program was developed on the basis of the theoretical formulation discussed above, for determining the in plane natural frequencies of vibration of a laminated circular composite beam. Using the generalized eigenvalue routine, the natural frequencies were obtained. The formulation was validated for both thin and thick circular composite beams. The material properties considered for various composite circular beams are presented in Table 1.

Table 1

The transversely isotropic material properties used in this study

\begin{tabular}{ccccccc}
\hline & $\mathrm{E}_{1}(\mathrm{GPa})$ & $\mathrm{E}_{2}=\mathrm{E}_{3}(\mathrm{GPa})$ & $\mathrm{G}_{12}(\mathrm{GPa})$ & $\mathrm{G}_{23}(\mathrm{GPa})$ & $v_{12}$ & $\rho\left(\mathrm{kgm}^{-3}\right)$ \\
\hline $\begin{array}{c}\text { Graphitc-Epoxy } \\
(\mathrm{T} 300 / 5208)\end{array}$ & 181 & 10.3 & 7.17 & 3.433 & 0.28 & 1600 \\
Kevlar49-Epoxy & 76 & 5.56 & 2.30 & 1.618 & 0.34 & 1460 \\
\hline
\end{tabular}




\subsection{Validation}

In order to validate and confirm the accuracy of the theory and the present frequencies, a circular beam made of an isotropic material with a singlc-layer is examined. The exact results for the frequencies are given by Chidamparam and Leissa /34/ and Tseng et al. $135 /$. The material and cross-sectional properties of the curved beam are as follows: $E=181 \mathrm{GPa}$, $v=0.3, \rho=1600 \mathrm{kgm}^{-3}, \alpha=100^{\circ}$, width=thickness $=0.5 \mathrm{~m}$, and radius $=50 \mathrm{~m}$.

Table 2 shows the lowest six dimensionless natural frequencies of fixed-fixed end boundary conditions using $\mathrm{E}_{1}=\mathrm{E}_{2}=\mathrm{E}_{3}=\mathrm{E}=181 \mathrm{GPa}, v_{12}=v=0.3, \mathrm{G}_{12}=\mathrm{G}_{23}=\mathrm{E} /(2(1+v))$ and $\beta=0^{\circ}$. It can be seen that the results obtained by the references $134-35 /$ and present study are comparable.

Table 2

Convergence of frequency parameters $\omega \mathrm{R}^{2} \sqrt{\rho \mathrm{A} / \mathrm{EI}}$ for a fixed-fixed circular beam for isotropy

\begin{tabular}{ccccccc}
\hline Methods & $\omega_{1}$ & $\omega_{2}$ & $\omega_{3}$ & $\omega_{4}$ & $\omega_{5}$ & $\omega_{6}$ \\
\hline Ref. $/ 34 /$ & 17.9249 & 34.6752 & 62.8782 & 92.8664 & $/$ & $/$ \\
Ref. $/ 35 /$ & 17.9154 & 34.6427 & 62.7886 & 92.6767 & 133.613 & 175.602 \\
Present & 17.8192 & 34.6194 & 63.3102 & 92.8944 & 134.027 & 175.934 \\
\hline \multicolumn{7}{c}{ "P" indicates that no data is available }
\end{tabular}

As a second example, a circular beam made of an isotropic material with single-layer is also analyzed for various thickness ratios. When the data used for the previous example are changed to the ones given by reference $/ 36 /: R=1 \mathrm{~m}, \alpha=120^{\circ}$, $\rho=1 \mathrm{kgm}^{-3}, \mathrm{E}=1 \mathrm{~Pa}$, with the dimensions of the cross-sections being $\mathrm{a}=0.25 \mathrm{~m}, \mathrm{~h}=0.01 \mathrm{~m}$ and the Poisson ratio $v=0.3$, then the lowest three natural frequencies for the fixed ends circular Timoshenko beam are calculated and shown in Table 3 . The results shown in Table 3 correspond to the five thickness ratios, $a / R=0.25,0.1,0.05,0.025,0.01$. The agreement with published results is very good.

Table 3

Lowest three natural frequencies for fixed-fixed Timoshenko circular beam for isotropic material

\begin{tabular}{ccccc}
$\begin{array}{c}\text { Thickness } \\
\text { ratio } \\
\mathrm{a} / \mathrm{R}\end{array}$ & Methods & \multicolumn{3}{c}{ Natural frequencies (rads $\left.{ }^{-1}\right)$} \\
\hline 0.250 & Ref. $/ 36 /$ & 0.6898 & 0.8225 & $\omega_{1}$ \\
& Present & 0.7115 & 0.8309 & 1.5181 \\
0.100 & Ref. $/ 36 /$ & 0.3284 & 0.5878 & 0.9811 \\
& Present & 0.3356 & 0.5942 & 0.9849 \\
0.050 & Ref. $/ 36 /$ & 0.1692 & 0.3295 & 0.6022 \\
& Present & 0.1718 & 0.3320 & 0.6082 \\
0.025 & Ref. $/ 36 /$ & 0.08528 & 0.1690 & 0.3076 \\
& Present & 0.08644 & 0.1701 & 0.3098 \\
0.010 & Ref. $/ 36 /$ & 0.03419 & 0.06808 & 0.1238 \\
& Present & 0.03290 & 0.06797 & 0.1242 \\
\hline
\end{tabular}




\subsection{Effect of h/a ratio}

In order to validate the present solution methodology, results for symmetric laminated circular beams are compared with the available solution obtained in reference $/ 17 /$. The cross sectional properties of the curved beam are thickness (a) $=0.2$ $\mathrm{m}$, and radius $(R)=5.7735 \mathrm{~m}$. The dimensionless frequency is defined as follows: $\bar{\omega}=\omega R^{2} \sqrt{\rho / E_{1} h^{2}}$. Results of the dimensionless fundamental frequencies of $\left(0^{\circ} / 90^{\circ} / 90^{\circ} / 0^{\circ}\right)$ laminated circular beams made of a Kevlar 49-epoxy material are shown in Table 4. As can be seen from this table, good agreements exist between the obtained results in this work and reference $/ 17 /$. It can be seen that as $h / a$ ratio increases, the frequencies decrease.

\section{Table 4}

Dimensionless fundamental in-plane natural frequencies $\left(\bar{\omega}=\omega \mathrm{R}^{2} \sqrt{\rho / \mathrm{E}_{1} \mathrm{~h}^{2}}\right)$ of $\left(0^{\circ} / 90^{\circ} / 90^{\circ} / 0^{\circ}\right)$ laminated circular beams with fixed-fixed ends at different $h / a$ ratios.

\begin{tabular}{cccc}
\hline$\alpha\left(^{0}\right)$ & Methods & $\mathrm{h} / \mathrm{a}=10$ & $\mathrm{~h} / \mathrm{a}=0.1$ \\
\hline 90 & Ref. $/ 17 /$ & 0.45592 & 45.59570 \\
& Present & 0.46154 & 46.17685 \\
180 & Ref. $/ 17 /$ & 0.09149 & 9.15578 \\
& Present & 0.09450 & 9.47588 \\
\hline
\end{tabular}

\subsection{Effect of boundary conditions for non-sy'mmetric laminates}

The frequencies of vibrations for non-symmetric laminated beams $\left(0^{\circ} / 90^{\circ} \% 0^{\circ} / 90^{\circ}\right)$ for various boundary conditions are presented in Table 5. The frequency values are calculated for the properties of Kevlar 49-epoxy. The cross sectional properties of the circular beam are width=thickness $=0.5 \mathrm{~m}$, radius $=5 \mathrm{~m}$, and opening angle $(\alpha)=180^{\circ}$. It can be seen that the fixed-free boundary condition has the lowest frequencies, as compared to the other boundary conditions considered. The Fixed-fixed boundary condition case has the largest natural frequencies. The vibration frequencies strongly depend on the boundary conditions.

Table 5

Lowest three natural frequencies of $\left(0^{0} / 90^{\circ} / 90^{\circ} / 0^{\circ}\right)$ non-symmetric laminated beams.

\begin{tabular}{cccc}
\hline Frequencies (Ilz) & $\begin{array}{c}\text { Fixed- } \\
\text { Fixed }\end{array}$ & $\begin{array}{c}\text { Fixed- } \\
\text { Hinged }\end{array}$ & $\begin{array}{c}\text { Fixed- } \\
\text { Free }\end{array}$ \\
\hline$\omega_{1}$ & 19.90208 & 15.27067 & 2.16214 \\
$\omega_{2}$ & 40.19024 & 35.96481 & 6.57760 \\
$\omega_{3}$ & 70.70477 & 65.45068 & 21.65663 \\
\hline
\end{tabular}

\subsection{Effect of composite properties}

In order to see how the composite properties for each layer change the natural frequencies, various values of Kevlar 49 and Graphite-epoxy were considered. The fundamental frequencies of $\left(0^{\circ} / 90^{\circ} / 90^{\circ} / 0^{\circ}\right)$ laminated circular beams made of $0^{\circ} \mathrm{Kevlar} / 90^{\circ} \mathrm{Graphite} / 90^{\circ} \mathrm{Graphite} / 0^{\circ} \mathrm{Kevlar}$ material and $0^{\circ} \mathrm{Graphite} / 90^{\circ} \mathrm{Kevlar} / 90^{\circ} \mathrm{Kevlar} / 0^{\circ} \mathrm{Graphite}$ are analyzed. The cross sectional properties of the circular beam are width=thickness $=0.5 \mathrm{~m}$, radius $=5 \mathrm{~m}$, and opening angle $(\alpha)=180^{\circ}$. Table 6 show's the comparison of in-plane frequency values $(\mathrm{Hz})$ under fixed-fixed boundary conditions for various orthotropic cross-ply configurations of each layer. The results presented in Table 6 indicate that the natural frequencies of Graphite-epoxy are the highest. The lowest frequencies are observed for the Kevlar-epoxy material. 
Table 6

Lowest three natural frequencies of $\left(0^{\circ} / 90^{\circ} / 90^{\circ} / 0^{\circ}\right)$ symmetric laminated beams using different material properties for fixed ends

\begin{tabular}{cccc}
\hline Frequencies (Hz) & $\mathrm{Kev} / \mathrm{Kev} / \mathrm{Kev} / \mathrm{Kev}$ & $\mathrm{Kev} / \mathrm{Graph} / \mathrm{Graph} / \mathrm{Kev}$ & $\mathrm{Graph} / \mathrm{Kev} / \mathrm{Kev} / \mathrm{Graph}$ \\
\hline$\omega !$ & 19.89248 & 20.97185 & 29.31549 \\
$\omega 2$ & 40.20074 & 43.19941 & 58.56046 \\
$\omega 3$ & 70.68472 & 77.76001 & 102.52200 \\
\hline
\end{tabular}

\section{CONCLUSIONS}

In this study, a functional for the in plane free vibration behavior of a cross-ply laminated curved composite beam is obtained by GDM. The mixed finite element formulation was developed and a computer program in Fortran language was coded to analyze the in-plane free vibrations. The finite element model consists of a total of six degrees of freedom, two displacements $\left(u_{n}, u_{l}\right)$, a rotation $\left(\Omega_{b}\right)$, two shear forces $\left(T_{n}, T_{t}\right)$ and a bending moment $\left(M_{b}\right)$. Using the proposed method. laminates of various boundary conditions are analyzed. The effect of different layer arrangements (symmetric and nonsymmetric) in laminated composite curved beams are compared for various boundary conditions and discussed. Natural frequencies of curved beam are computed using the mixed finite element formulation on the basis of Timoshenko beam theory including the shear deformation. The formulation has been validated for both thin and thick circular composite beams. At the same time this formulation can be used for wide and relatively thin structures due to the fact that this formulation is free from locking effects. Because of the properties of the functional obtained by GDM, it is possible to generate element matrices easily. The results of natural angular frequencies of laminated composite circular beams are compared by solving various simple problems for which solutions are available in the literature. An excellent agreement is achieved. The formulation presented is general in nature and the method therefore may be utilized for general geometry of curved composite beams.

\section{REFERENCES}

1. M.R. Jones, Mechanics of Composite Materials, Taylor \& Francis, 1999.

2. J.N. Reddy, Mechanics of Laminated Composite Plates and Shells: Theory and Analysis, 2nd ed. Boca Raton, FL: CRC Press, 2004.

3. G. Shi, K.Y. Lam. Finite element vibration analysis of composite beams based on higher- order beam theory. Journal of Sound and Vibration 1999; 219(4):707-721.

4.V. Yildirim, E. Sancaktar, E. Kiral. Free Vibration analysis of symmetric cross-ply laminated composite beams with the help of the transfer matrix approach. Communications in Numerical Methods in Engineering 1999; 15:651660.

5. G.S. Ramtekkar, Y.M. Desai. Natural vibrations of laminated composite beams by using mixed finite element modeling. Journal of Sound and Vibration 2002;257(4):635-651.

6. W.Q. Chen, C.F. Lv, Z.G. Bian. Elasticity solution for free vibration of laminated beams. Composite Structures 2003; 62:75-82.

7. W.Q. Chen, C.F. Lv, Z.G. Bian. Free vibration analysis of generally laminated beams via state-space-based differential quadrature. Composite Structures 2004; 63:417-425.

8. M. Aydogdu. Vibration analysis of cross-ply laminated beams with general boundary conditions by Ritz method. Int.J.of Mechanical Sciences 2005; 47:1740-1755. 
9. P. Subramanian. Dynamic analysis of laminated composite beams using higher order theories and finite elements. Composite Structures 2006; 73:342-353.

10. R.A. Jafari-Talookolaei, M.T. Ahmadian. Free vibration analysis of a cross-ply laminated composite beam on Pasternak foundation. Journal of Computer Science 2007; 3(1):51-56.

11. S.R. Marur, T. Kant. On the angle ply higher order beam vibrations. Comput. Mech. 2007; 40:25-33.

12. J.G. Kim. An effective composite laminated curved beam element. Communications in numerical methods in engineering 2006; 22:453-466.

13. K.C. Lin, C.M. Hsich., The closed form general solutions of 2-D curved laminated beams of variable curvatures. Composite Structure 2007; 79:606-618.

14. H. Matsunaga. Free vibration and stability of laminated composite circular arches subjected to initial axial stress. Journal of Sound and Vibration 2004; 271:651-670.

15. Y.P. Tseng, C.S. Huang, M.S. Kao. In-plane vibration of laminated curved beams with variable curvature by dynamic stiffness analysis. Composite Structure 2000; 50:103-114.

16. V. Yildirim. Rotary inertia, axial and shear deformation effects on the in-plane natural frequencies of symmetric cross-ply laminated circular arches. Journal of Sound and Vibration 1999; 224(4):575-589.

17. V. Yildirim. In-plane free vibration of symmetric cross-ply laminated circular bars. Journal of Engineering Mechanics 1999; 125(6):630-636.

18. M.S. Qatu. In-plane vibration of slightly curved laminated composite beams. Journal of Sound and Vibration 1992; 159:327-338.

19. M.S. Qatu, A.A. Elsharkawy. Vibration of laminate composite arches with deep curvature and arbitrary boundaries. Computers and Structures 1993; 47:305-311.

20. M.S. Qatu. Theories and analyses of thin and moderately thick laminated composite beams. International Journal of Solids and Structures 1993; 30:2743-2756.

21. R.K. Kapania, S. Raciti. Non-linear vibrations of unsymmetrically laminated beams. AIAA J. 1989; 27(2):201210.

22. A. K. Miller, D. F. Adams. An analytic means of determining the flexural and torsional resonant frequencies of generally orthotropic beams. Journal of Sound Vibration 1975; $41: 433-449$.

23. A.T. Chen, T.Y. Yang. Static and dynamic formulation of symmetrically laminated beam finite element for microcomputer. J.Compos. Mater. 1985; 19:459-475.

24. K. Chandrashekhara, K. Krishnamurty. S. Roy, Free vibration of composite beams including rotary inertia and shear deformation. Composite Structure 1990; 14:269-279.

25. K. Chandrashekhara, K. M. Bangera. Free vibration of composite beams using refined shear flexible beam element. Computers and Structures 1992; 43(4):719-727.

26. A. A. Khdeir, J. N. Reddy. Free vibration of cross-ply laminated beams with arbitrary boundary conditions. Int. J. Eng. Sci. 1994; 32(12):1971-1980.

27. A.Y. Akoz, F. Kadioglu. The mixed finite element solution of circular beam on elastic foundation. Computers and Structures 1996; 60(4):643-651.

28. A.Y. Akoz, F. Kadioglu. The mixed finite element method for the quasi-static and dynamic analysis of viscoelastic Timoshenko beams. International Journal for Numerical Methods in Engineering 1999; 44(12):1909-1932.

29. F. Kadioglu, A.Y. Akoz. The mixed finite element method for the quasi-static and dynamic analysis of viscoelastic circular beams. An International Journal, Structura Engineering and Mechanics 2003; 15(6):735-752.

30. M.H. Omurtag, F. Kadioglu. Free vibration analysis of orhotropic plates resting on Pasternak foundation by mixed finite element formulation. Computers and Structures 1998; 67:253-265.

31. V.Yildirim. Governing equations of initially twisted elastic space rods made of laminated composite materials. International Journal of Engineering Science 1999; 37:1007-1035. 
32. J.D. Oden, J.N. Reddy. Variational Method in Theoretical Mechanics, Springer, Berlin, 1976.

33. N. Heubner, The Finite Element Method for Engineers, Wiley, New York, 1975.

34. P. Chidamparam, A.W. Leissa. Influence of centerline extensibility on the in-plane free vibrations of loaded circular arches. Journal of Sound and Vibration 1975; 183:779-795.

35. Y.P. Tseng, C.S. Huang, C.J. Lin. Dynamic stiffness analysis for in-plane vibrations of arches with variable curvature. Journal of Sound and Vibration 1997; 207(1):15-31.

36. J.S. Wu, L.K. Chiang. A new approach for free vibration analysis of arches with effects of shear deformation and rotary inertia considered. Journal of Sound and Vibration 2004;277:49-71. 
